\title{
Comparison between Solar and Artificial Photocatalytic Decolorization of Textile Industrial Wastewater
}

\author{
Falah H. Hussein \\ Chemistry Department, College of Science, Babylon University, Iraq \\ Correspondence should be addressed to Falah H. Hussein, abohasan_hilla@yahoo.com \\ Received 5 February 2012; Revised 15 April 2012; Accepted 24 April 2012 \\ Academic Editor: Jiaguo Yu
}

Copyright () 2012 Falah H. Hussein. This is an open access article distributed under the Creative Commons Attribution License, which permits unrestricted use, distribution, and reproduction in any medium, provided the original work is properly cited.

The photocatalytic decolorization of industrial wastewater was investigated by using $\mathrm{TiO}_{2}$ and $\mathrm{ZnO}$ photocatalysts. Heterogeneous photocatalytic processes applied under natural weathering conditions, in the presence of solar radiation show a promising degradation capability. The complete removal of color could be achieved in a relatively short time of about 20 minutes, when $\mathrm{ZnO}$ was used and about 100 minutes when $\mathrm{TiO}_{2}$ was used under solar irradiation. However, in the presence of artificial UV-light, complete decolorization of textile industrial wastewater was obtained after less than one hour of irradiation when $\mathrm{ZnO}$ was used and in less than two hours, when $\mathrm{TiO}_{2}$ was used at the same temperature. The results indicate that the degree of photocatalytic decolorization of textile industrial wastewater was obviously affected by different parameters. These parameters include catalyst mass, type of catalyst, type of reactor, type of dye, dye concentration, and temperature. The procedure used in this research can be used as an efficient technology for solar photocatalytic decolorization of the colored wastewater discharged from the textile industry under the climatic conditions of most countries.

\section{Introduction}

Treatments of industrial wastewater, especially textile wastewater, will provide huge amount of water to face water scarcity around the world. Moreover the reliable treatments of wastewater will reduce contamination of soils, surface, and ground water, and as a result public health will be protected. Textile wastewaters are strongly colored and contain high amounts of organic matter depending on forms of dyes and auxiliary chemicals $[1,2]$.

Titanium dioxide and zinc oxide are widely and economically available. These semiconductors can be excited with light of a wavelength in the range of the solar spectrum $(\lambda>310 \mathrm{~nm})$. Using of solar irradiation is very attractive technology from the economical point of view.

Titanium dioxide and zinc oxide are universally considered as the most important photocatalysts, due to their considerably low bandgap energy $(\sim 3.2 \mathrm{eV})$ and their lower cost. However, various methods have been developed to reduce the band gap and the electron-hole recombination. Jing et al. [3] reported that the photocatalytic activity of the semiconductor is strongly dependent on its crystallite size, specific surface area, morphologies, and textures. The photocatalytic activity of $\mathrm{ZnO}$ hollow spheres with porous crystalline shells was increased significantly compared with untreated samples of $\mathrm{ZnO}$ at ambient temperature [4]. The hierarchical organization of nanosheets together with annealing-induced carbon doping within the $\mathrm{ZnO}$ lattice accounting for the improved visible light photocatalytic activity of porous carbon self-doped $\mathrm{ZnO}$ consequently gave better photocatalytic activity of $\mathrm{ZnO}$ products [5]. The photocatalytic properties of titanium dioxide are improved significantly in the presence of high energy facets, making this material attractive for various environmental applications [6]. The surface structure at the atomic level plays an important role in tuning the adsorption selectivity and, consequently, photocatalytic activity of semiconductor [7]. Graphene-based semiconductor photocatalysts also have important environmental and energy applications [8]. Titanium dioxide response toward visible light was increased after the addition of silver using the hydrothermal synthesis due to the formation of $\mathrm{Ag}$ aggregation on the $\mathrm{TiO}_{2}$ surface 


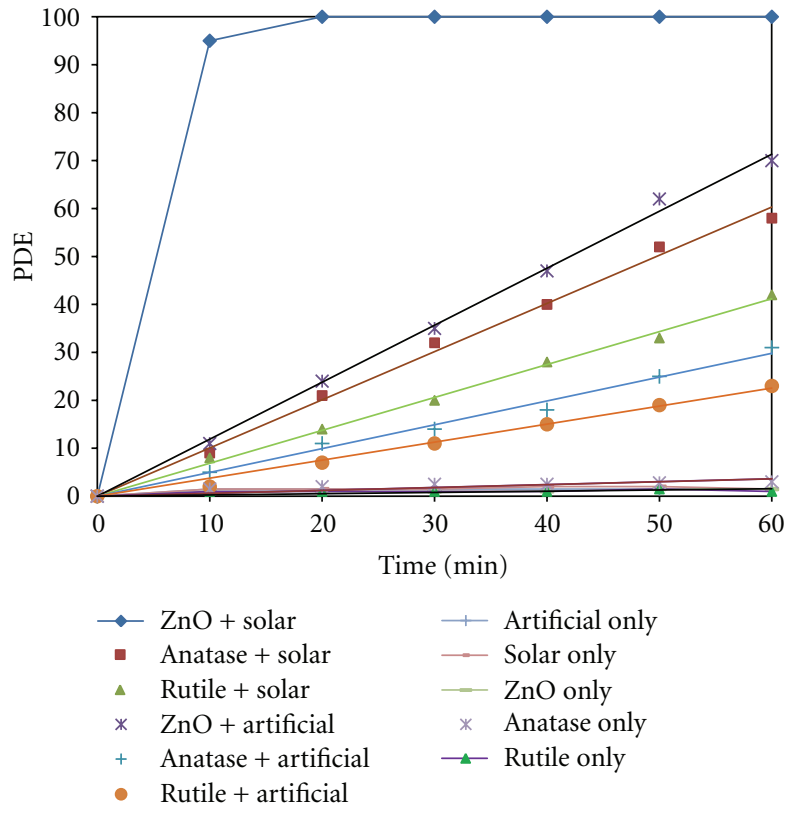

FIGURE 1: Effect of types of catalyst and irradiation on photocatalytic decolorization efficiency of real industrial wastewater.

[9]. The photocatalytic activity of titanium dioxide is also significantly enhanced by those embedding gold nanoparticles in the $\mathrm{Au}-\mathrm{TiO}_{2}$ nanocomposites. The prepared $\mathrm{Au}-\mathrm{TiO}_{2}$ nanocomposites exhibit a highly visible light photocatalytic activity, and their photocatalytic activity is higher than that of the pristine $\mathrm{TiO}_{2}$ nanoparticles due to the surface plasmon resonance [10]. Wang et al. [11] reported that photocatalytic activity of $\mathrm{TiO}_{2}$ powders calcined at $500^{\circ} \mathrm{C}$ was two times higher than that of the uncalcined $\mathrm{TiO}_{2}$. The authors explained that this was due to the enhancement of anatase crystallization and the optimal mass ratio (ca. 1:2) of rutile to anatase.

The band gap of metalized titanium dioxide prepared by a simple impregnation method was reduced to $2.80 \mathrm{eV}$. Moreover, the solar decolorization and mineralization rates for $\mathrm{Ta} / \mathrm{TiO}_{2}$ - and $\mathrm{Nb} / \mathrm{TiO}_{2}$-mixed oxide photocatalysts were improved by about $140 \%$ and $237 \%$, respectively compared with untreated Degussa P25 TiO 2 [12].

The prepared carbon-modified $\mathrm{TiO}_{2}$ powders by impregnation method using a commercial available titania powder, Hombikat UV100, as matrix material, showed better photoactivity of nitrogen oxides degradation than that of unmodified $\mathrm{TiO}_{2}$ [13]. Comparing with the untreated $\mathrm{TiO}_{2}$, anatase mesoporous titanium dioxide codoped with nitrogen and chlorine $\left(\mathrm{N}-\mathrm{Cl}-\mathrm{TiO}_{2}\right)$ greatly improves the photoresponse of $\mathrm{TiO}_{2}$, thereby reducing the band gap [14]. The authors explained the enhancement of photocatalytic activity due to the small crystalline size, intense light absorption in visible region, and narrow band gap [14].

Wang et al. [15] in a recent review mentioned that doping of metal and nonmetal elements can improve the photocatalytic activity of titanium dioxide.

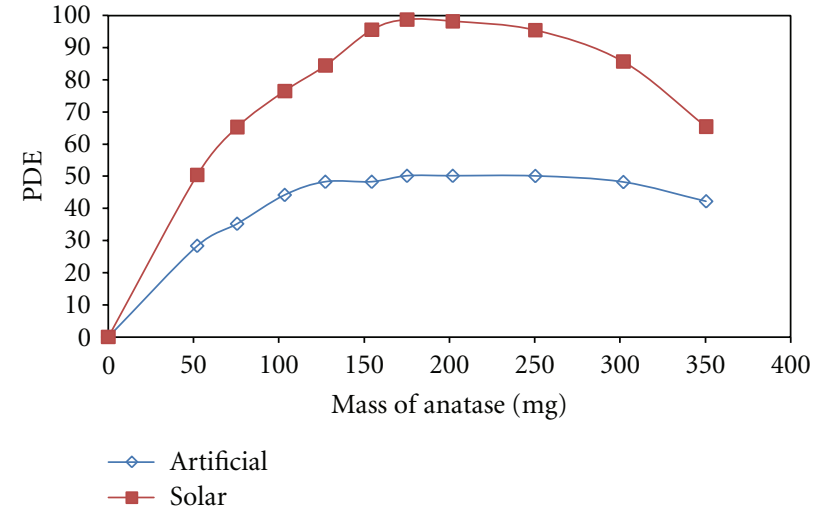

Figure 2: Mass effect of $\mathrm{TiO}_{2}$ (anatase) on photocatalytic decolorization efficiency of real textile industrial wastewater for different times of irradiation under solar and artificial radiation.

Solar disinfection (SODIS) is a simple and low-cost technique used to disinfect drinking water. It was found that this important technique was enhanced in the existence of photocatalysts by far more effective way than SODIS alone for the inactivation of both the total coliforms and the faecal coliforms [16].

Low $\mathrm{pH}$ and high concentration of $\mathrm{Cl}^{-}$solutions were found beneficial to the photocatalytic activity of titanium dioxide [17].

By monitoring the surface chemistry of $\mathrm{Pt}-\mathrm{TiO}_{2}$ microspheres before and after photocatalytic reactions, it was found that the degradation of methyl orange molecules was more complete in the presence of platinum particles on the surface of titanium dioxide [18].

We have investigated previously, prolifically, the decolorization, photodegradation, and phytoremediation of many water-soluble toxic compounds in real and simulated industrial wastewater. The treated wastewaters could be recycled in the same industry or reused in another industry or for agricultural fields. The efficiency of these methods of treatments is between 70 and 95\% [19-29].

The aim of the present paper is to investigate photocatalytic decolorization of real and simulated textile wastewater using $\mathrm{TiO}_{2}$ and $\mathrm{ZnO}$ as photocatalysts with irradiation with solar and artificial radiation at different conditions.

\section{Experimental Procedure}

Real textile industrial wastewater sample was collected at the mid of December 2008 from textile factory in Hilla (Babylon Governorate, Iraq) at the discharging point. The sample was collected in hydrochloric acid-washed polyethylene container, $10 \mathrm{dm}^{-3}$ in volume, which previously washed for several times with nitric acid $(0.05 \mathrm{~N})$ and rinsed for several times with redistilled water.

Experiments were carried out during December 2008 till July 2009. Solar irradiation experiments have been performed at the floor of the Chemistry Department building in the College of Science, Babylon University, in an open atmosphere between $11.00 \mathrm{a} . \mathrm{m}$. and $1.00 \mathrm{p} . \mathrm{m}$. 


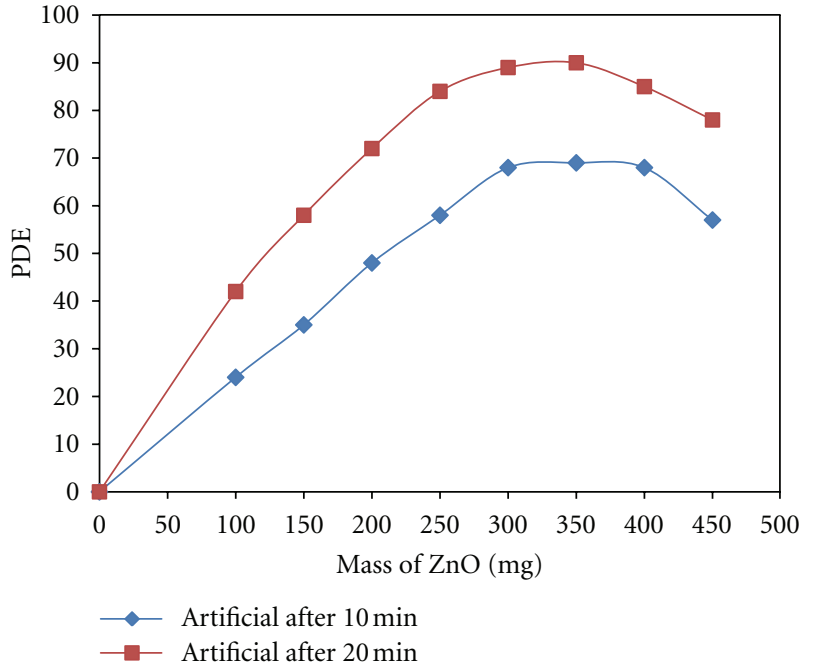

(a)

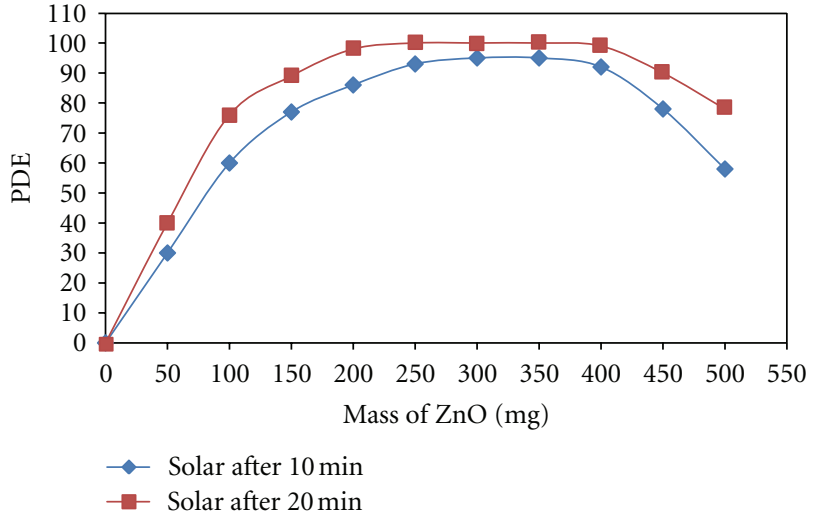

(b)

Figure 3: Mass effect of $\mathrm{ZnO}$ on photocatalytic decolorization efficiency of real textile industrial wastewater for different times of irradiation under artificial radiation (a) and solar irradiation (b).

Sunlight illuminations were accomplished in a $300 \mathrm{~cm}^{3}$ glass container containing $100 \mathrm{~cm}^{3}$ of the industrial wastewater solution. The sunlight radiation was collected using converging lens with a focal length of $14 \mathrm{~cm}$. Artificial irradiation experiments are performed in a homemade reactor. The reactor consists of graduated $400 \mathrm{~cm}^{3}$ Pyrex glass beaker and a magnetic stirring setup. The radiation source was a Philips $125 \mathrm{w} / 542$ high-pressure mercury lamp (Holland). The lamp was positioned perpendicularly above the beaker. The mercury lamp was allowed to warm up for 3 minutes to ensure a stable light intensity before commencing a reaction.

Titanium dioxide P-25 anatase (commercial $\mathrm{TiO}_{2}$ ), of surface area $50 \mathrm{~m}^{2} \mathrm{~g}^{-1}$, was purchased from Degussa. Titanium dioxide rutile was obtained from Fluka (Assay 97\%) and zinc oxide with $99.5 \%$ purity, supplied by Carlo ERBA.

In all experiments, the required amount of the catalyst, titanium dioxide (anatase or rutile) or zinc oxide, was suspended in $100 \mathrm{~cm}^{3}$ of industrial wastewater using a magnetic stirrer. At predetermined times, $1.5 \mathrm{~cm}^{3}$ of reaction mixture was collected and centrifuged $(4,000 \mathrm{rpm}, 15$ minutes) in an $800 \mathrm{~B}$ centrifuge. The supernatant was carefully removed by a syringe with a long pliable needle and centrifuged again at same speed and for the same period of time. This second centrifugation was found necessary to remove fine particles of $\mathrm{ZnO}$ or $\mathrm{TiO}_{2}$. After the second centrifugation, the absorbance at certain wavelengths of the supernatants was determined using ultraviolet-visible spectrophotometer, type UV-1650 PC, Shimadzu and visible spectrophotometer type v-1000, T-Chromatech.

Photocatalytic decolorization efficiency (PDE) of the dye was followed, spectrophotometrically, by a comparison of the absorbance, at specified interval times, with a calibration curve accomplished by measuring the absorbance, at known wavelengths, with different concentrations of the dye solution. PDE is calculated from a mathematical equation

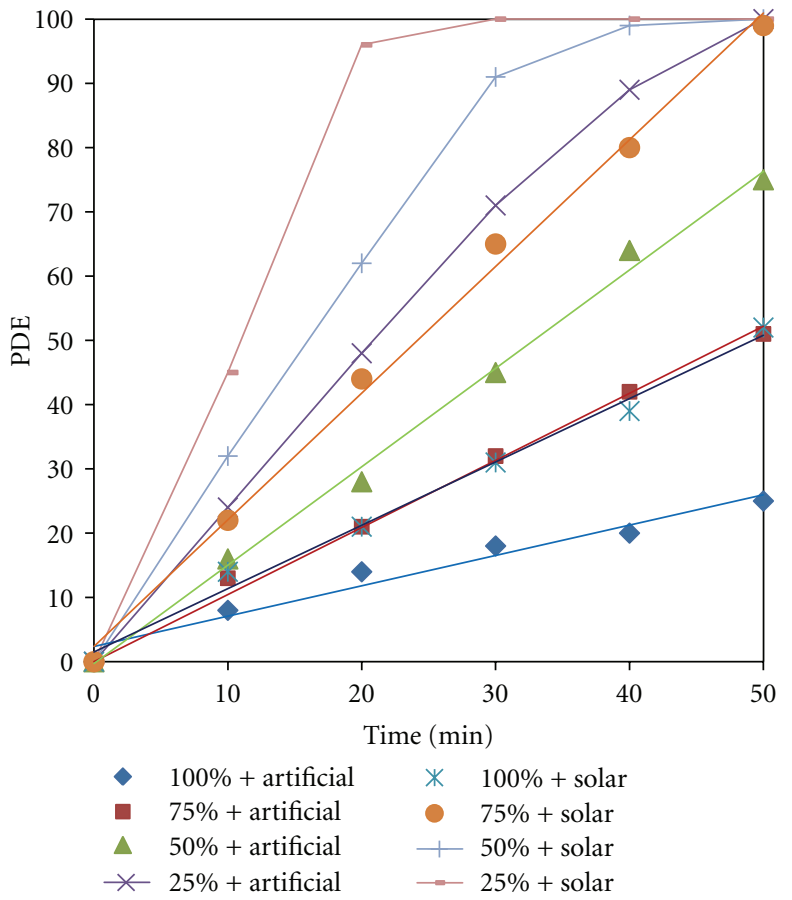

FIgURE 4: Effect of initial dye on photocatalytic decolorization of real textile industrial wastewater on $\mathrm{TiO}_{2}$ (anatase) and solar radiation.

adapted from measurements of decolorization used before $[30,31]$.

$$
\mathrm{PDE}=\frac{(\text { absorbance })_{0}-(\text { absorbance })_{t}}{(\text { absorbance })_{0}} \times 100,
$$

where (absorbance) $)_{0}$ is the absorbance at $422 \mathrm{~nm}$ before irradiation and (absorbance) $)_{t}$ is the absorbance at time $t$. To 


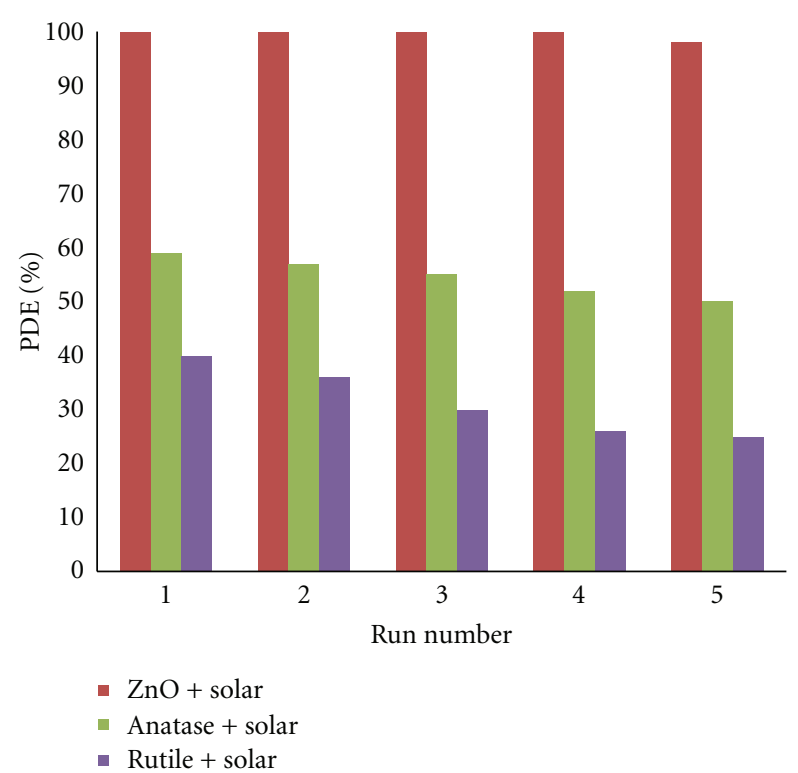

Figure 5: Effect of $\mathrm{TiO}_{2}$ (anatase and rutile) and zinc oxide reuse on photocatalyic decolorization efficiency after 60 minutes of solar irradiation.

TABLE 1: Effect of temperature on photocatalytic decolorization efficiency of real textile industrial wastewater on $\mathrm{TiO}_{2}$ and solar radiation.

\begin{tabular}{lcccc}
\hline \multirow{2}{*}{ Time/min. } & \multicolumn{4}{c}{ Temperature/K } \\
& 293.15 & 298.15 & 304.15 & 310.15 \\
\hline 0 & 0 & 0 & 0 & 0 \\
10 & 9.11 & 11.23 & 12.43 & 14.22 \\
20 & 18.23 & 20.88 & 23.54 & 26.44 \\
30 & 26.66 & 30.43 & 34.05 & 39.76 \\
40 & 36.55 & 40.22 & 46.12 & 55.45 \\
50 & 45.65 & 51.65 & 58.54 & 70.34 \\
60 & 55.24 & 58.34 & 65.45 & 78.85 \\
\hline
\end{tabular}

check the validity of the previous equation for used textile industrial wastewater, the photodegradation percentage of the dye was followed, spectrophotometrically, by a comparison of the absorbance, at specified interval times, with a calibration curve accomplished by measuring the absorbance, at known wavelengths, with different concentrations of the dye solution.

\section{Results and Discussion}

3.1. Photocatalytic Decolorization of Real Textile Industrial Wastewater at Different Conditions. Figure 1 shows the change in photocatalytic decolorization efficiency (PDE) of real textile industrial wastewater in the present and absent of catalyst and in the present and absent of solar or artificial irradiation.

The results indicate that the activity of different catalysts fell in the sequence:
TABLE 2: Effect of temperature on photocatalytic decolorization efficiency of real textile industrial wastewater on $\mathrm{ZnO}$ and artificial radiation.

\begin{tabular}{lcccc}
\hline \multirow{2}{*}{ Time/min } & \multicolumn{4}{c}{ Temperature/K } \\
& 290.15 & 298.15 & 313.15 & 319.15 \\
\hline 0 & 0 & 0 & 0 & 0 \\
10 & 10.22 & 12 & 17.25 & 18.22 \\
20 & 21.4 & 14.12 & 35.25 & 38.04 \\
30 & 32.8 & 36.22 & 52.33 & 56.22 \\
40 & 42.44 & 48.35 & 68.88 & 77.25 \\
50 & 52.3 & 62.55 & 85.25 & 100 \\
60 & 63.55 & 72.85 & 97.88 & 100 \\
\hline
\end{tabular}

$\mathrm{ZnO}($ solar $)>\mathrm{ZnO}($ artificial $)>$ Anatase $($ solar $)>$ Rutile (solar) > Anatase (artificial) > Rutile (artificial) $\gg$ No catalyst $=$ No solar or artificial irradiation $=0$.

These results also indicate that there was no dark reaction. Incubations of colored industrial wastewater without solar or artificial radiation and/or without catalyst was performed to demonstrate that decolorization of the dye was dependent on the presence of both; light and catalyst.

Results indicate that $\mathrm{ZnO}$ in the existence of solar irradiation is most active. Sakthivel et al. [32] explained the higher activity of $\mathrm{ZnO}$ due to absorption of large fraction of the solar spectrum and absorption of more light quanta by $\mathrm{ZnO}$ than $\mathrm{TiO}_{2}$. However, the amount of zinc oxide required to reach the optimum activity is two times more than that for titanium dioxide (anatase or rutile) $[25,26]$. In another study, Attia et al., [23], observed that $\mathrm{ZnO}$ is less active than anatase when the same weight of catalysts is used for photocatalytic degradation of textile wastewater. Akyol et al., [33] reported that $\mathrm{ZnO}$ is more active than $\mathrm{TiO}_{2}$ for the decolorization efficiency of aqueous solution of a commercial textile dye due to the band gap energy, the charge carrier density, and the crystal structure.

All types of catalysts used in this research showed higher photocatalytic activity under sunlight irradiation. This may be due to high light intensity of solar radiation in IRAQ. Neppolian et al. [34] reported that solar energy may emerge as a viable method for textile wastewater treatment because of its eco-friendliness and cost effective where 96\% of textile industrial wastewater was photodegradated during April-June; peak summer period of the year in Chennai, India. However, Akbal [35] concluded that the photocatalytic decolorization rate of methylene blue and methyl orange with UV light irradiation was higher than that with solar light irradiation.

3.2. Effect of Catalyst Mass. Figure 1 shows that $175 \mathrm{mg}$ of anatase is sufficient for maximum rate of decolorization when mercury lamp was used for irradiation. Moreover the same mass was found also sufficient when the reaction vessel was illuminated with solar irradiation. These observations proved that the optimum mass to achieve maximum decolorization percentage is independent on type of irradiation 


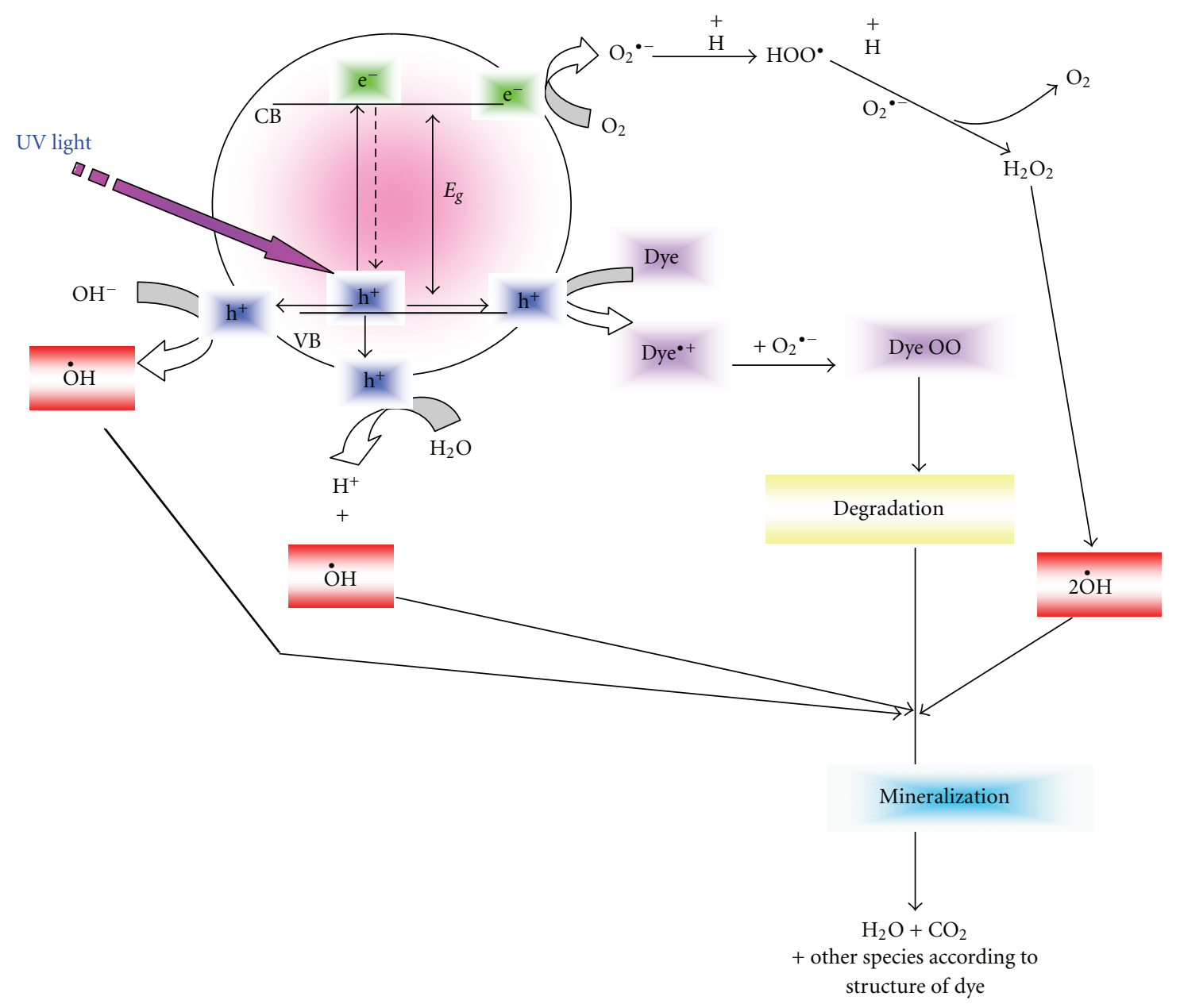

Scheme 1: Dye/semiconductor/UV light system.

source and solar irradiation in this system is more efficient than $125 \mathrm{w} / 542$ high pressure mercury lamp.

The same observations were noted when $\mathrm{ZnO}$ was used as photocatalyst. However the optimum mass to achieve maximum PDE is $350 \mathrm{mg}$. These results are shown in Figure 2.

Mass of catalyst is regarded as the major parameter affecting the photocatalytic degradation efficiency [36]. The results plotted in Figures 2 and 3 shows that the photocatalytic degradation efficiency of real industrial wastewater increases linearly with the increasing in catalysts mass at the first stages. This behavior may be due to an increase in the amount of active site on surface of photocatalyst particles and as a result, the number of dye molecule that adsorbed on the surface of photocatalyst will be increased and that will lead to an increase in the density of particles in the area of illumination [37]. However, after reaching maximum photocatalytic degradation rate, addition of excess amount of catalysts has no effect on photocatalytic rate, so a plateau region was observed. After the plateau region is achieved, the activity of photocatalytic decolorization decrease with increase of catalyst concentration for titanium dioxide and zinc oxide. This behavior is more likely due to Light scattering by catalyst particles at higher concentration which leads to decrease in the passage of irradiation through the sample leading to poor light utilization $[38,39]$. Deactivation of activated photocatalyst molecules colliding ground state molecules with increasing the load of photocatalyst may be also cause reduction in photocatalyst activity [37]. High concentration of loading catalyst also decreases the number of surface active sites [40].

3.3. Effect of Temperature. Reaction was followed at four different temperatures in the range 293.15-315.15 K using $175 \mathrm{mg}$ of anatase under solar radiation. The results in Table 1 indicate that the PDE of real textile industrial wastewater increases with increasing of temperature.

Reaction was also followed at four different temperatures in the range $290.15-319.15 \mathrm{~K}$ using mercury lamp and $350 \mathrm{mg}$ of zinc oxide. The results are listed in Table 2. The results indicate that $\mathrm{PDE}$ of real textile industrial wastewater increases with increasing of temperature. However it is clear that temperature is the least active parameter in the photocatalytic decolorization of real textile industrial wastewater. 


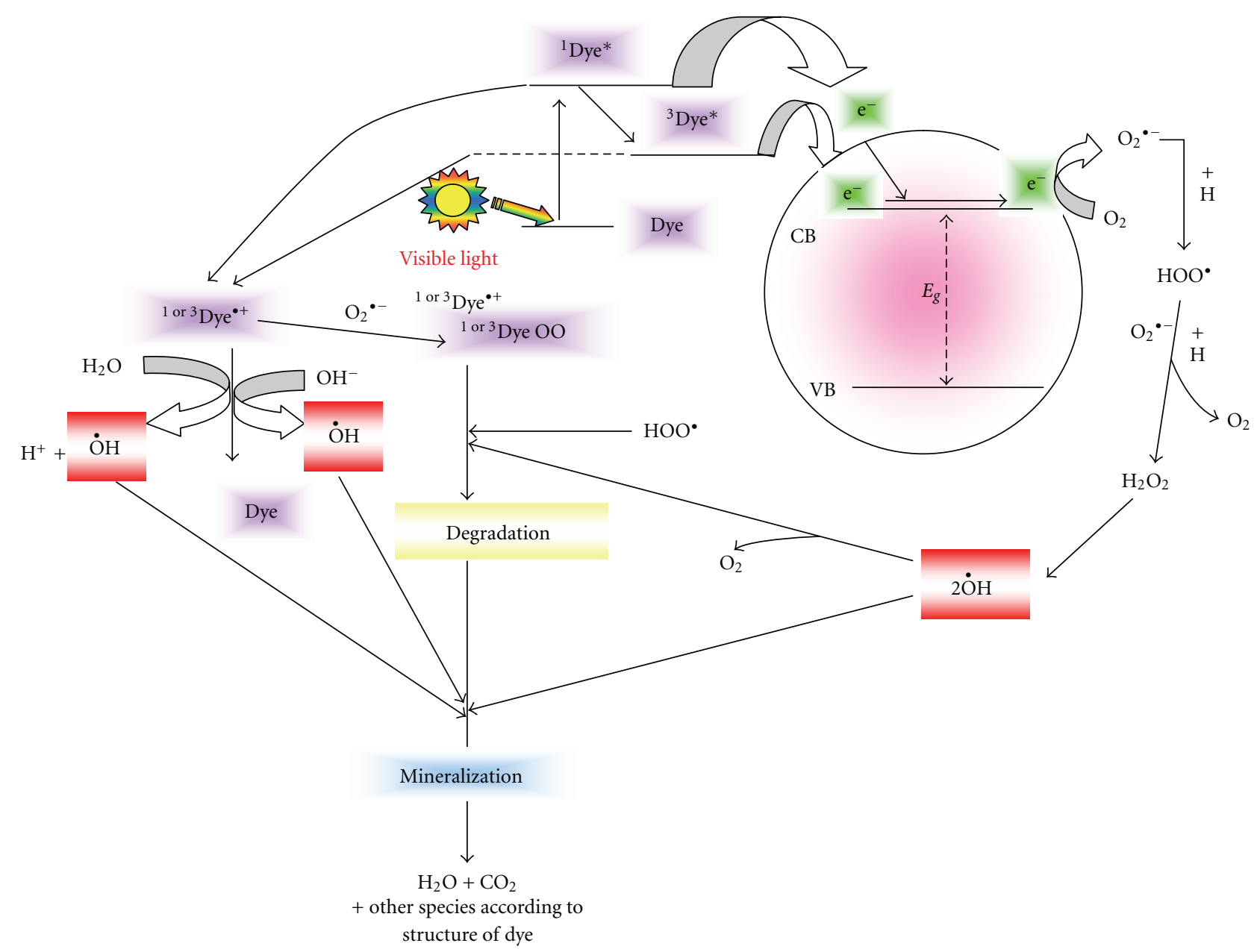

Scheme 2: Nonregenerative dye/semiconductor/visible light system.

It is well known that the most desirable system for complete mineralization of a wide range of organic substrates is that which operates under natural weathering conditions without producing of harmful byproducts [41]. Photocatalytic treatments and especially with solar irradiation offer that because they are mostly proceeding under natural weathering conditions. Adsorption of reactants on the surface of catalysts is a spontaneous exothermic phenomenon so it is enhanced by reduction of temperature [42].

3.4. Effect of Initial Dye Concentration. The results in Figure 4 show the changing of rate of decolorization of real textile industrial wastewater on $175 \mathrm{mg}$ of anatase by using solar and artificial irradiation at $298.15 \mathrm{~K}$ with the initial direct dye concentrations $(25 \%-100 \%)$ at different times. The results indicate that decreasing of dye concentration decreases the time of decolorization.

This behavior related to decreasing of the path length of photons entering the solution as the initial concentration of dye increases, and as a result the number of photon absorbed by the catalyst decreases.

This behavior related to decreasing of the path length of photons entering the solution as the initial concentration of dye increases, and as a result the number of photon reached the catalyst surface decreases [43-45].

3.5. The Reusability of Catalyst. The reusability of the titanium dioxide (anatase or rutile) and zinc oxide was examined. The recovered catalysts were reused for five consecutive runs. Figure 5 shows only a slight decrease in the activity of these photocatalysts after five consecutive uses. However, rutile showed more decrease than anatase and zinc oxide.

\section{Kinetics of Decolorization}

In photosensitization process, which is defined as the conversion of light energy to chemical reactivity [46], a colored organic or inorganic material is added to a semiconductor. The added sensitizer (Sens) absorbs light in to the visible range to yield an excited state of the sensitizer (Sens)*. The excited sensitizing molecule injects an electron from excited singlet (S1) or triplet (T1) states into the conduction band of the semiconductor [47].

The illumination of suspended semiconductor in an aqueous solution of dye with unfiltered light (polychromatic light) leads to the possibility of the existence of two pathways $[21,48]$. 


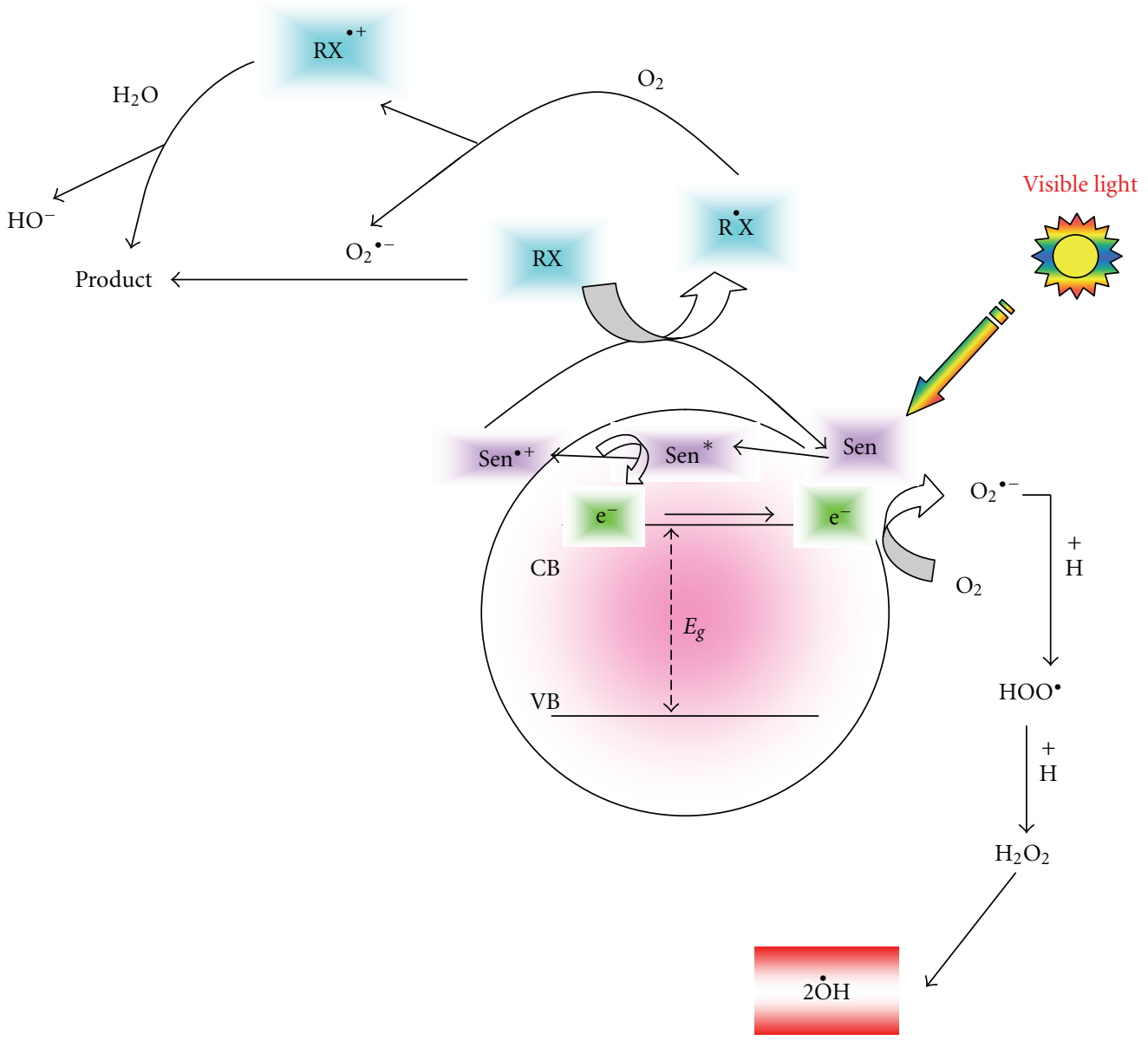

Scheme 3: Regenerative dye/semiconductor/visible light system.

(1) In the first pathway, the part of light with energy equal to or more than the band gap of the illuminated semiconductor will cause a promotion of an electron to conduction band of the semiconductor, and as a result, a positive hole will be created in the valence band. The formed photoholes and photoelectrons can move to the surface of the semiconductor in the presence of light energy. The positive hole will react with adsorbed water molecules on the surface of semiconductor producing ${ }^{\bullet} \mathrm{OH}$ radicals, and the electron will react with adsorbed oxygen on the surface. Moreover, they can react with deliquescent oxygen and water in suspended liquid and produce perhydroxyl radicals $\left(\mathrm{HO}_{2}{ }^{\bullet}\right)$ with high chemical activity [49]. The processes in this pathway, as shown in Scheme 1, can be summarized by the following equations:

$$
\begin{gathered}
\mathrm{h}^{+}+\mathrm{OH}^{-} \longrightarrow \dot{\mathrm{O}} \mathrm{H} \\
\mathrm{h}^{+}+\mathrm{H}_{2} \mathrm{O} \longrightarrow \mathrm{H}^{+}+\dot{\mathrm{O}} \mathrm{H} \\
\mathrm{e}^{-}+\mathrm{O}_{2} \longrightarrow \mathrm{O}_{2}^{\cdot-} \\
\mathrm{O}_{2}^{\cdot-}+\mathrm{H}^{+} \longrightarrow \mathrm{HO}_{2}^{\cdot} \\
\mathrm{HO}_{2}^{\cdot}+\mathrm{O}_{2}^{\cdot-} \stackrel{\mathrm{H}^{+}}{\longrightarrow} \mathrm{H}_{2} \mathrm{O}_{2}+\mathrm{O}_{2}
\end{gathered}
$$

$$
\mathrm{H}_{2} \mathrm{O}_{2} \longrightarrow 2 \dot{\mathrm{O}} \mathrm{H}
$$

Dye + Semiconductor $\left(\mathrm{h}^{+}{ }_{\mathrm{VB}}\right) \longrightarrow \mathrm{Dye}^{\bullet+}+$ Semiconductor

$$
\mathrm{Dye}^{\bullet+}+\mathrm{O}_{2}{ }^{\bullet-} \longrightarrow \mathrm{DO}_{2} \longrightarrow \text { degradation products }
$$

(2) In the second pathway, the other part of light with energy which is less than the band gap of the illuminated semiconductor will be absorbed by the adsorbed dye molecules. Dye molecules will be decolorized by a photosensitization process. The photocatalytic decolorization of dyes, which is described as photosensitization processes, is also characterized by a free radical mechanism. In this process, the adsorbed dyes molecules on the surface of the semiconductor can absorb a radiation in the visible range in addition to the radiation with short wavelengths $[19,50,51]$. The excited colored dye (dye*) (in the singlet or triplet state) will inject an electron to the conduction band of the semiconductor [24]. The processes in this pathway, as shown in Scheme 2, can be summarized by the following equations:

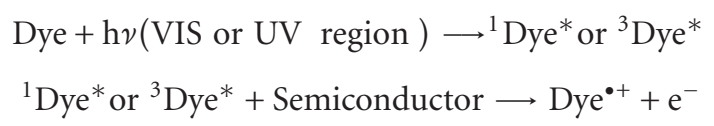

(to the conduction band of Semiconductor) 


$$
\begin{gathered}
\mathrm{e}^{-}+\mathrm{O}_{2} \longrightarrow \mathrm{O}_{2}{ }^{--}+\text {Semiconductor } \\
\text { Dye }^{\bullet+}+\mathrm{O}_{2}{ }^{\bullet-} \longrightarrow \mathrm{DO}_{2} \longrightarrow \text { degradation products } \\
\text { Dye }^{++}+\mathrm{HO}_{2}^{\bullet}(\text { or } \mathrm{H} \dot{\mathrm{O}}) \longrightarrow \text { degradation products } \\
\text { Dye }+2 \dot{\mathrm{O}} \mathrm{H} \longrightarrow \mathrm{H}_{2} \mathrm{O}+\text { oxidation products } \\
\text { Dye }^{\bullet+}+{ }^{-} \mathrm{OH} \longrightarrow \text { Dye }+\dot{\mathrm{O}} \mathrm{H} \\
\text { Dye }^{\bullet+}+\mathrm{H}_{2} \mathrm{O} \longrightarrow \text { Dye }+\dot{\mathrm{O}} \mathrm{H}+\mathrm{H}^{+}
\end{gathered}
$$

The mechanism above is favoured by nonregenerative organic dye where dye/semiconductor/visible light system and the sensitizer itself degrade. However, in regenerative semiconductor system, (Scheme 3), the following mechanism may be followed:

$$
\begin{aligned}
& \text { Sen }+\mathrm{TiO}_{2} \longleftrightarrow \text { Sen }-\mathrm{TiO}_{2} \\
& \text { Sen }-\mathrm{TiO}_{2}+\mathrm{RX} \longleftrightarrow \text { Sen }-\mathrm{TiO}_{2} \cdots \mathrm{RX}(\mathrm{ads}) \\
& \text { Sen }-\mathrm{TiO}_{2}+\mathrm{O}_{2} \longleftrightarrow \text { Sen }-\mathrm{TiO}_{2} \cdots \mathrm{O}_{2(\text { ads })} \\
& \text { Sen }-\mathrm{TiO}_{2} \underset{\mathrm{h} v}{\stackrel{\mathrm{h} v}{\underset{\rightleftarrows}{\rightleftarrows}}} \stackrel{\text { visible light }}{\underset{ }{\rightleftarrows}} \mathrm{Sen}^{*}-\mathrm{TiO}_{2} \\
& \text { Sen }{ }^{*}-\mathrm{TiO}_{2} \cdots \mathrm{O}_{2(\mathrm{ads})} \longrightarrow \mathrm{Sen}^{+}-\mathrm{TiO}_{2}+\mathrm{O}_{2}{ }^{-} \\
& \mathrm{Sen}^{+}-\mathrm{TiO}_{2}+\mathrm{O}_{2}{ }^{-} \longrightarrow \mathrm{Sen}-\mathrm{TiO}_{2}+\mathrm{O}_{2} \\
& \text { Sen }{ }^{*}-\mathrm{TiO}_{2} \longrightarrow \mathrm{Sen}^{+}-\mathrm{TiO}_{2}\left(\mathrm{e}_{\mathrm{C} . \mathrm{B}}^{-}\right) \\
& \mathrm{Sen}^{+}-\mathrm{TiO}_{2}\left(\mathrm{e}_{\mathrm{C} . \mathrm{B}}^{-}\right) \longrightarrow \mathrm{Sen}-\mathrm{TiO}_{2} \\
& \mathrm{Sen}^{+}-\mathrm{TiO}_{2}\left(\mathrm{e}_{\mathrm{C} . \mathrm{B}}^{-}\right) \cdots \mathrm{RX} \longrightarrow \mathrm{Sen}^{+}-\mathrm{TiO}_{2}+\dot{\mathrm{R}} \mathrm{X}+\mathrm{X}^{-} \\
& \mathrm{Sen}^{+}-\mathrm{TiO}_{2}\left(\mathrm{e}_{\mathrm{C} . \mathrm{B}}^{-}\right) \cdots \mathrm{O}_{2(\mathrm{ads})} \longrightarrow \mathrm{Sen}^{+}-\mathrm{TiO}_{2}+\mathrm{O}_{2}{ }^{-}
\end{aligned}
$$

Cho et al. [52] conclude that there is no direct electron transfer between an excited sensitizer and $\mathrm{CCl}_{4}$ molecules, in homogeneous solution, and the existence of semiconductor is essential for sensitized photocatalysis. Platinum supported on titanium dioxide acts as an excellent sensitizer and could have practical advantages as a mild and convenient photocatalyst for selective oxidation processes [53]. The addition of rhodamine $\mathrm{B}$, as sensitizer to $\mathrm{TiO}_{2}$ dispersion system, increases the rate of photooxidation properties [54]. The authors explained that due to the fact that more light absorbed by rhodamine B between 460 and $580 \mathrm{~nm}$, then the energy transfer from sensitizer to $\mathrm{TiO}_{2}$ or to any other active species hence promotes the photocatalytic activity of titanium dioxide.

\section{Conclusions}

(1) The existence of catalyst and lights is essential for photocatalytic degradation of colored dyes.
(2) Solar photocatalytic treatment is an efficient technique for decolorization of industrial wastewater through a photocatalytic process, and the transformation is practically complete in a reasonable irradiation time.

(3) Visible light/ZnO and visible light/ $/ \mathrm{TiO}_{2}$ systems could be efficiently used for photodegradation of textile industrial wastewater. The results indicate that the degree of photodegradation of textile industrial wastewater was obviously affected by different parameters. The complete removal of color could be achieved in a relatively short time of about 20 minutes, when $\mathrm{ZnO}$ was used under solar irradiation.

(4) The procedure used in this research can be used as an efficient technology for solar photocatalytic degradation of the colored wastewater discharged from the textile industry under natural weathering conditions.

\section{Acknowledgments}

The author is gratefully acknowledging the financial support provided by the Arab Science and Technology Foundation (ASTF) and the US Civilian Research and Development Foundation (CRDF) without which this research would not have been possible. The author also expresses sincere appreciation to all the staff working at ASTF, Baghdad Office. This paper was Published in Proceedings of ISES, Solar World Congress, 2011: Kassel-Germany (28th August-2nd September, 2011).

\section{References}

[1] S. Meriç, D. Kaptan, and T. Ölmez, "Color and COD removal from wastewater containing Reactive Black 5 using Fenton's oxidation process," Chemosphere, vol. 54, no. 3, pp. 435-441, 2004.

[2] M. Muruganandham and M. Swaminathan, "Decolourisation of reactive orange 4 by fenton and photo-Fenton oxidation technology," Dyes and Pigments, vol. 63, no. 3, pp. 315-321, 2004.

[3] L. Jing, Y. Qu, B. Wang et al., "Review of photoluminescence performance of nano-sized semiconductor materials and its relationships with photocatalytic activity," Solar Energy Materials and Solar Cells, vol. 90, no. 12, pp. 1773-1787, 2006.

[4] J. Yu and X. Yu, "Hydrothermal synthesis and photocatalytic activity of zinc oxide hollow spheres," Environmental Science and Technology, vol. 42, no. 13, pp. 4902-4907, 2008.

[5] S. Liu, C. Li, J. Yu, and Q. Xiang, "Improved visible-light photocatalytic activity of porous carbon self-doped $\mathrm{ZnO}$ nanosheet-assembled flowers," CrystEngComm, vol. 13, no. 7, pp. 2533-2541, 2011.

[6] S. Liu, J. Yu, and M. Jaroniec, "Anatase $\mathrm{TiO}_{2}$ with dominant high-energy 001 facets: synthesis, properties, and applications," Chemistry of Materials, vol. 23, no. 18, pp. 4085-4093, 2011.

[7] S. Liu, J. Yu, and M. Jaroniec, "Tunable photocatalytic selectivity of hollow $\mathrm{TiO}_{2}$ microspheres composed of anatase polyhedra with exposed 001 facets," Journal of the American Chemical Society, vol. 132, no. 34, pp. 11914-11916, 2010. 
[8] Q. Xiang, J. Yu, and M. Jaroniec, "Graphene-based semiconductor photocatalysts," Chemical Society Reviews, vol. 41, no. 2, pp. 782-796, 2012.

[9] C. A. Castro, A. Jurado, D. Sissa, and S. A. Giraldo, "Performance of $\mathrm{Ag}-\mathrm{TiO}_{2}$ photocatalysts towards the photocatalytic disinfection of water under interior-lighting and solar-simulated light irradiations," International Journal of Photoenergy, vol. 2012, Article ID 261045, 10 pages, 2012.

[10] M. Zhou, J. Zhang, B. Cheng, and H. Yu, "Enhancement of visible-light photocatalytic activity of mesoporous $\mathrm{Au}-\mathrm{TiO}_{2}$ nanocomposites by surface plasmon resonance," International Journal of Photoenergy, vol. 2012, Article ID 532843, 10 pages, 2012.

[11] G. Wang, L. Xu, J. Zhang, T. Yin, and D. Han, "Enhanced photocatalytic activity of $\mathrm{TiO}_{2}$ powders (P25) via calcination treatment," International Journal of Photoenergy, vol. 2012, Article ID 265760, 9 pages, 2012.

[12] H. Znad, M. H. Ang, and M. O. Tade, "Ta/TiO 2 -and Nb/TiO ${ }_{2}$ mixed oxides as efficient solar photocatalysts: Preparation, characterization, and photocatalytic activity," International Journal of Photoenergy, vol. 2012, Article ID 548158, 9 pages, 2012.

[13] C. Huang, Y. Lin, I. Wang, and C. Lu, "Photocatalytic activity and characterization of carbon-modified titania for visiblelight-active photodegradation of nitrogen oxides," International Journal of Photoenergy, vol. 2012, Article ID 548647, 13 pages, 2012.

[14] X. Cheng, X. Yu, Z. Xing, and L. Yang, "Enhanced visible light photocatalytic activity of mesoporous anatase $\mathrm{TiO}_{2}$ codoped with nitrogen and chlorine," International Journal of Photoenergy, vol. 2012, Article ID 593245, 6 pages, 2012.

[15] J. Wang, Q. Cai, H. Li, Y. Cui, and H. Wang, "A review on $\mathrm{TiO}_{2}$ nanotube film photocatalysts prepared by liquid-phase deposition," International Journal of Photoenergy, vol. 2012, Article ID 702940, 11 pages, 2012.

[16] J. A. Byrne, P. A. Fernandez-Ibañez, P. S. M. Dunlop, D. M. A. Alrousan, and J. W. J. Hamilton, "Photocatalytic enhancement for solar disinfection of water: a review," International Journal of Photoenergy, vol. 2011, Article ID 798051, 12 pages, 2011.

[17] X. Wu, Z. Huang, Y. Liu, and M. Fang, "Investigation on the photoelectrocatalytic activity of well-aligned $\mathrm{TiO}_{2}$ nanotube arrays," International Journal of Photoenergy, vol. 2012, Article ID 832516, 7 pages, 2012.

[18] J. Zhang, L. Li, and G. Li, "Enhancing photocatalytic performance through tuning the interfacial process between $\mathrm{TiO}_{2}$ assembled and Pt-loaded microspheres," International Journal of Photoenergy, vol. 2012, Article ID 913630, 7 pages, 2012.

[19] A. N. Alkhateeb, F. H. Hussein, and K. A. Asker, "Photocatalytic decolonization of industrial wastewater under natural weathering conditions," Asian Journal of Chemistry, vol. 17, no. 2, pp. 1155-1159, 2005.

[20] A. Alkhateeb, J. Ismail, and F. Hussein, "Solar photolysis and photocatalytic degradation of murexide using titanium dioxide and zinc oxide," JAAUBAS, vol. 4, pp. 70-76, 2007.

[21] F. H. Hussein, A. N. Alkhateeb, and J. K. Ismail, "Solar photolysis and photocatalytic decolorization of thymol blue," E-Journal of Chemistry, vol. 5, no. 2, pp. 243-250, 2008.

[22] F. Al-Zahra, A. N. Alkhateeb, and F. H. Hussein, "Photocatalytic oxidation of benzyl alcohol using pure and sensitized anatase," Desalination, vol. 209, no. 1-3, pp. 342-349, 2007.

[23] A. J. Attia, S. H. Kadhim, and F. H. Hussein, "Photocatalytic degradation of textile dyeing wastewater using titanium dioxide and zinc oxide," E-Journal of Chemistry, vol. 5, no. 2, pp. 219-223, 2008.
[24] F. H. Hussein and A. N. Alkhateeb, "Photo-oxidation of benzyl alcohol under natural weathering conditions," Desalination, vol. 209, no. 1-3, pp. 350-355, 2007.

[25] F. Hussein and T. Abbas, "Photocatalytic treatment of textile industrial wastewater," International Journal of Chemical Sciences, vol. 8, no. 3, pp. 1353-1364, 2010.

[26] F. H. Hussein and T. Abbas, "Solar photolysis and photocatalytic treatment of textile industrial wastewater," International Journal of Chemical Sciences, vol. 8, no. 3, pp. 1409-1420, 2010.

[27] F. H. Hussein, A. F. Halbus, H. A. K. Hassan, and W. A. K. Hussein, "Photocatalytic degradation of bismarck brown $\mathrm{G}$ using irradiated $\mathrm{ZnO}$ in aqueous solutions," E-Journal of Chemistry, vol. 7, no. 2, pp. 540-544, 2010.

[28] F. H. Hussein, M. Obies, and A. Drea, "Photocatalytic decolorization of bismarck brown $\mathrm{R}$ by suspension of titanium dioxide," International Journal of Chemical Sciences, vol. 8, no. 4, pp. 2736-2746, 2010.

[29] F. H. Hussein, M. Obies, and A. Drea, "Photocatalytic decolorization of bismarck brown $\mathrm{R}$ by suspension of titanium dioxide," International Journal of Chemical Sciences, vol. 8, no. 4, pp. 2763-2774, 2010.

[30] P. F. F. Amaral, D. L. A. Fernandes, A. P. M. Tavares et al., "Decolorization of dyes from textile wastewater by Trametes versicolor," Environmental Technology, vol. 25, no. 11, pp. 1313-1320, 2004.

[31] D. Hongve and G. Åkesson, "Spectrophotometric determination of water colour in hazen units," Water Research, vol. 30, no. 11, pp. 2771-2775, 1996.

[32] S. Sakthivel, B. Neppolian, M. V. Shankar, B. Arabindoo, M. Palanichamy, and V. Murugesan, "Solar photocatalytic degradation of azo dye: comparison of photocatalytic efficiency of $\mathrm{ZnO}$ and $\mathrm{TiO}_{2}$," Solar Energy Materials and Solar Cells, vol. 77, no. 1, pp. 65-82, 2003.

[33] A. Akyol, H. C. Yatmaz, and M. Bayramoglu, "Photocatalytic decolorization of remazol red $\mathrm{RR}$ in aqueous $\mathrm{ZnO}$ suspensions," Applied Catalysis B, vol. 54, no. 1, pp. 19-24, 2004.

[34] B. Neppolian, H. C. Choi, S. Sakthivel, B. Arabindoo, and V. Murugesan, "Solar light induced and $\mathrm{TiO}_{2}$ assisted degradation of textile dye reactive blue 4," Chemosphere, vol. 46, no. 8 , pp. 1173-1181, 2002.

[35] F. Akbal, "Photocatalytic degradation of organic dyes in the presence of titanium dioxide under UV and solar light: effect of operational parameters," Environmental Progress, vol. 24, no. 3, pp. 317-322, 2005.

[36] D. Dong, P. Li, X. Li et al., "Investigation on the photocatalytic degradation of pyrene on soil surfaces using nanometer anatase $\mathrm{TiO}_{2}$ under UV irradiation," Journal of Hazardous Materials, vol. 174, no. 1-3, pp. 859-863, 2010.

[37] T. Kim and M. Lee, "Effect of $\mathrm{pH}$ and temperature for photocatalytic degradation of organic compound on carboncoated $\mathrm{TiO}_{2}$," International Journal of Advances in Engineering and Technology, vol. 3, no. 2, pp. 193-198, 2010.

[38] U. Gaya, A. Abdullah, Z. Zainal, and M. Hussein, "Photocatalytic degradation of 2,4-dichlorophenol in irradiated aqueous $\mathrm{ZnO}$ suspension," International Journal of Chemistry, vol. 2, no. 1, pp. 180-193, 2010.

[39] S. K. Kavitha and P. N. Palanisamy, "Photocatalytic and sonophotocatalytic degradation of reactive red 120 using dye sensitized $\mathrm{Tio}_{2}$ under visible light," International Journal of Civil and Environmental Engineering, vol. 3, pp. 1-6, 2011.

[40] R. S. Thakur, R. Chaudhary, and C. Singh, "Fundamentals and applications of the photocatalytic treatment for the removal of industrial organic pollutants and effects of operational 
parameters: a review," Journal of Renewable and Sustainable Energy, vol. 2, no. 4, Article ID 042701, pp. 42-70, 2010.

[41] S. K. Kansal, M. Singh, and D. Sud, "Comparative evaluation of UV/solar light induced photodegradation of phenol in aqueous solutions," Indian Chemical Engineering, vol. 49, no. 1, pp. 11-20, 2007.

[42] S. Malato, J. Blanco, A. Vidal et al., "Applied studies in solar photocatalytic detoxification: an overview," Solar Energy, vol. 75, no. 4, pp. 329-336, 2003.

[43] R. J. Davis, J. L. Gainer, G. O’Neal, and I. W. Wu, "Photocatalytic decolorization of wastewater dyes," Water Environment Research, vol. 66, no. 1, pp. 50-53, 1994.

[44] L. Rideh, A. Wehrer, D. Ronze, and A. Zoulalian, "Photocatalytic degradation of 2-chlorophenol in $\mathrm{TiO}_{2}$ aqueous suspension: modeling of reaction rate," Industrial and Engineering Chemistry Research, vol. 36, no. 11, pp. 4712-4718, 1997.

[45] V. Murugesan and S. Sakthivel, "Photocatalytic degradation of leather dyes in aqueous solution using solar/UV illuminated $\mathrm{TiO}_{2} / \mathrm{ZnO}$," in Proceedings of the International Symposium on Environmental Pollution Control and Waste Management (EPCOWM '02), pp. 654-659, Tunis, January 2002.

[46] T. Dahl, "Examining the role of singlet oxygen in photosensitized cytotoxity," in Aquatic and Surface Photochemistry, G. Heiz, R. Zepp, and D. Crosby, Eds., pp. 241-260, Lewis, Chelsea, Mich, USA, 1994.

[47] P. Kamat, "Photochemical solar cells; a successful marriage between semiconductor nanoclusters and excited dyes," APS Newsletter, pp. 1-11, 1996.

[48] F. H. Hussein, "Photochemical treatments of textile industries wastewater," in Advances in Treating Textile Effluent, P. J. Hauser, Ed., pp. 117-144, InTech Open Access Publishing, Vienna, Austria, 2011.

[49] M. Zhao and J. Zhang, "Wastewater treatment by photocatalytic oxidation of nano-ZnO," Global Environmental Policy in Japan, no. 12, pp. 1-9, 2008.

[50] P. Fernández-Ibáñez, J. Blanco, S. Malato, and F. J. de Las Nieves, "Application of the colloidal stability of $\mathrm{TiO}_{2}$ particles for recovery and reuse in solar photocatalysis," Water Research, vol. 37, no. 13, pp. 3180-3188, 2003.

[51] T. Ohno, "Preparation of visible light active S-doped $\mathrm{TiO}_{2}$ photocatalysts and their photocatalytic activities," Water Science and Technology, vol. 49, no. 4, pp. 159-163, 2004.

[52] Y. Cho, W. Choi, C. H. Lee, T. Hyeon, and H. I. Lee, "Visible light-induced degradation of carbon tetrachloride on dyesensitized $\mathrm{TiO}_{2}$," Environmental Science and Technology, vol. 35, no. 5, pp. 966-970, 2001.

[53] F. H. Hussein, G. Pattenden, R. Rudham, and J. J. Russell, "Photo-oxidation of alcohols catalysed by platinised titanium dioxide," Tetrahedron Letters, vol. 25, no. 31, pp. 3363-3364, 1984.

[54] F. Hussein, S. Radi, and S. Naman, "The effect of sensitizer on the photocatalytical oxidation of propan-2-ol by $\mathrm{Pt}^{-\mathrm{TiO}_{2}}$ and other catalysts," in Solar Energy Applications, Bioconversion and Sun Fules, vol. B of Energy and Environmental Progress 1, pp. 337-353, Nova Science, 1991. 


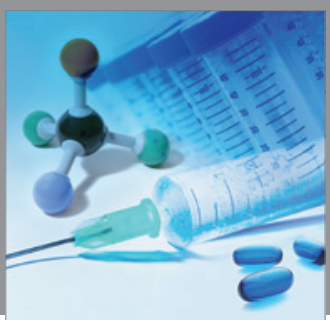

International Journal of

Medicinal Chemistry

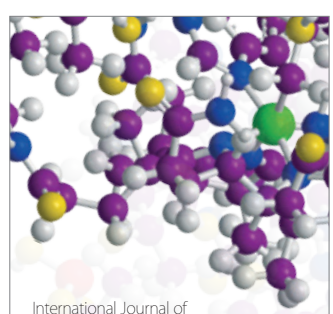

Carbohydrate Chemistry

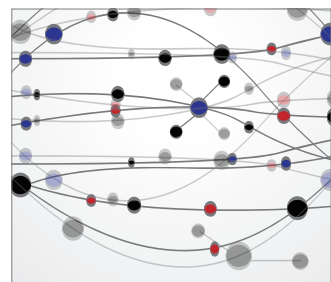

The Scientific World Journal
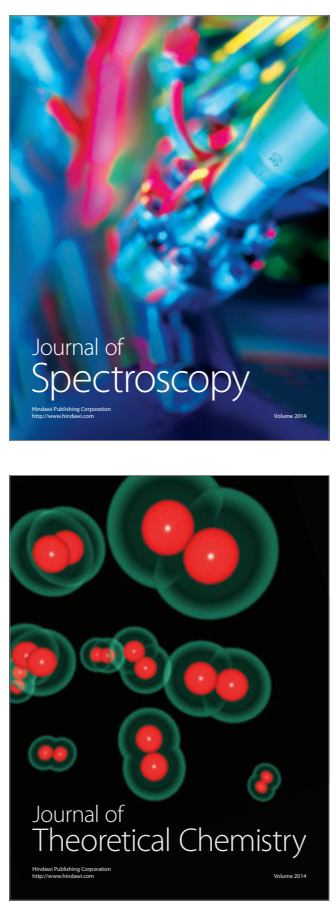
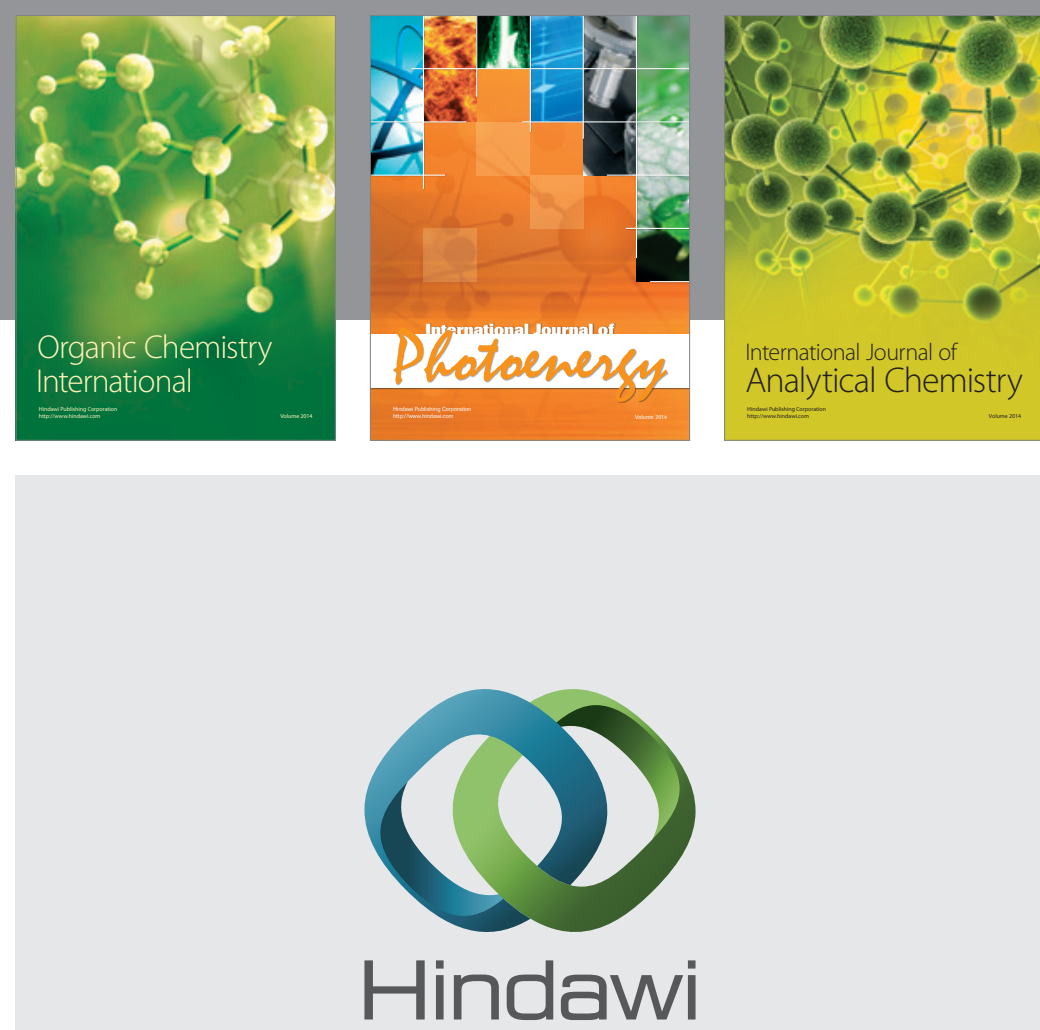

Submit your manuscripts at

http://www.hindawi.com
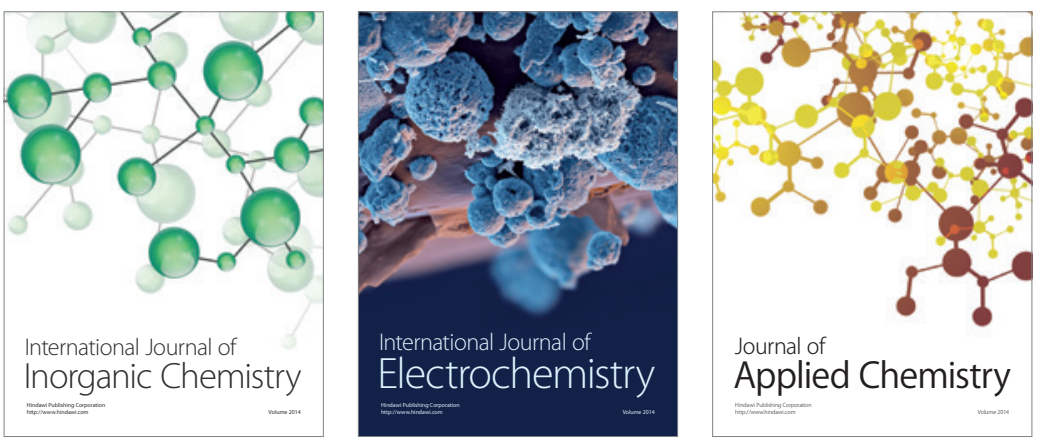

Journal of

Applied Chemistry
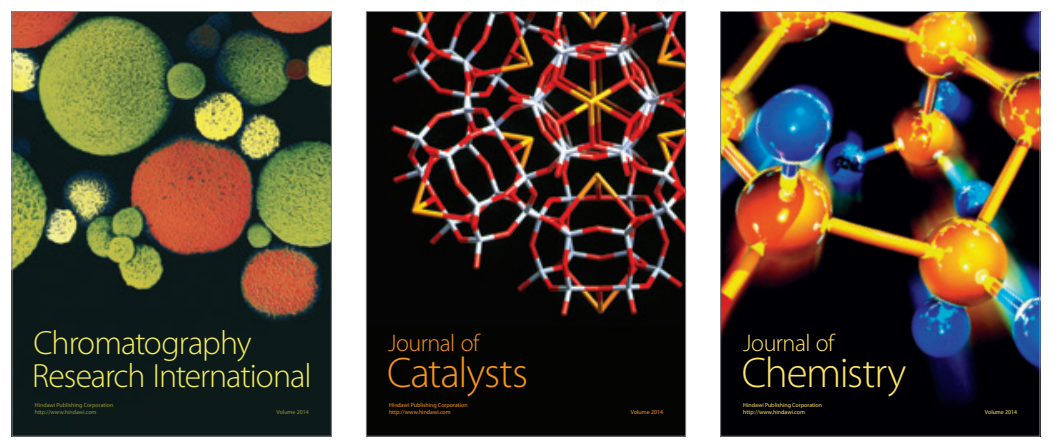
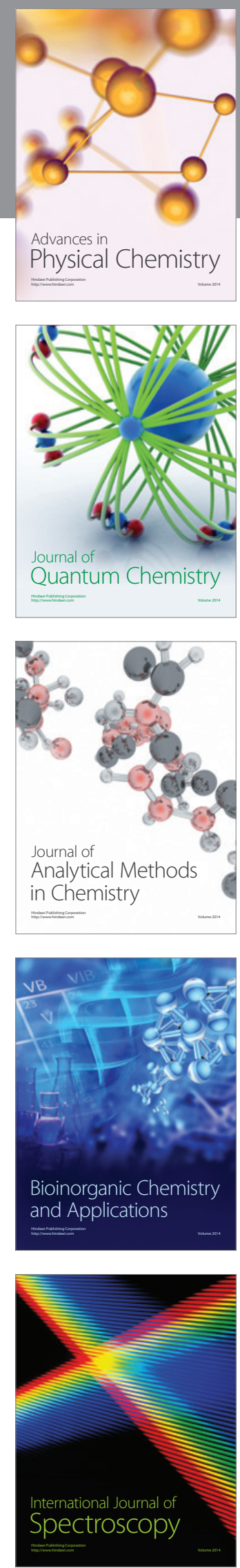